\title{
Red List assessment of nine Aegilops species in Armenia
}

\author{
Margarita Haruntyunyan • \\ Mohammad Ehsan Dulloo • \\ Naire Yeritsyan · Armen Danielyan
}

Received: 1 June 2009/Accepted: 29 March 2010/Published online: 23 April 2010

(C) The Author(s) 2010. This article is published with open access at Springerlink.com

\begin{abstract}
The aims of this study are to determine the geographical and ecological distribution of nine Aegilops species in Republic of Armenia and to make an assessment of their IUCN Red List status, using the IUCN Red list categories and criteria, in order to develop an in situ conservation strategy for wild relatives of wheat in Armenia. Ecogeographic surveys of nine Aegilops species were undertaken over 2 years in Armenia. They included a herbarium survey followed by extensive ground-truthing field surveys where targeted Aegilops species occur. The study showed that of the nine Aegilops species studied, four are threatened and of these, Ae. mutica and Ae. crassa are critically endangered. The latter species may even be extinct in Armenia. Ae. neglecta and $A$. biuncialis are endangered. Additional studies are required to assess the threat status of Ae. umbellulata. Ae. columnaris was assessed as near threatened, while the remaining species (Ae. triuncialis, Ae. cylindrica and Ae. tauschii) are of least
\end{abstract}

\footnotetext{
M. Haruntyunyan

Armenian State Agrarian University, Teryan str. 74, Yerevan 0009, Republic of Armenia

M. E. Dulloo ( $\square)$

Bioversity International, Via dei Tre denari 472/a, 00057 Maccarese, Rome, Italy

e-mail: e.dulloo@cgiar.org

N. Yeritsyan · A. Danielyan

Ministry of Nature Protection, Charents 46 str.,

Yerevan 0025, Republic of Armenia
}

concern. There has been a dramatic decline in the genetic resources of Aegilops species during recent years in Armenia as a result of adverse human impacts such as expansion of agriculture, urbanization and uncontrolled grazing. Several species, especially Ae. mutica and Ae. crassa, should be prioritized in conservation activities in Armenia. Efforts should be made to conserve genetic diversity of crop wild relative species both in situ and ex situ, bearing in mind that their germplasm carries potentially valuable information (traits) that can improve adaptability and productivity of cultivated wheat varieties.

Keywords Aegilops - Armenia . Crop wild relatives - Ecogeographic surveys · Red List · Wheat

\section{Introduction}

Wheat is the second most important staple food for a third of the world's people. Originating in the Fertile Crescent, wild relatives of wheat extend into West Asia and the Caucasus. Although wild relatives are important sources of genetic diversity that can help broaden the genetic base of cultivated wheat (Triticum aestivum L. [bread wheat] and T. durum Desf. [durum wheat]) (Hedge et al. 2002), they have not been adequately conserved or utilized. The primary gene pool of wheat comprises of four wild species: Triticum 
dicoccoides (Koern.) Koern. (wild emmer wheat), T. urartu Tumanian ex Gandilyan, T. araraticum Jakubz. (Syn: Triticum timopheevii (Zhuk.) Zhuk. ssp. araraticum (Jakubz.) MacKey) and Triticum boeoticum Boiss. (wild einkorn wheat; Syn: T. monococcum L. ssp. aegilopoides [Link] Thell.), and their domesticated forms in the genus Triticum L. (Hedge et al. 2002). The genus Aegilops constitute most of the secondary gene pool of wheat (Harlan and de Wet 1971). Genetic studies have provided firm evidence that Aegilops species are the donors of the B and D genomes of hexaploid wheat and have made an important contribution to the development of polyploid wheat cultivars (Dvorak and Zhang 1990). Economically valuable characteristics, particularly cold tolerance and resistance to drought, pests and diseases, make them invaluable for breeding.

The genus Aegilops L. belongs to the Poaceae family. They have narrowly cylindrical, lanceolate or ovate spikes. Aegilops are typical of semi-desert and mountain-steppe zones, where they grow on dry, rocky hillsides, along roadsides, at the edges of wheat cultivations and forests, in wastelands and at elevations ranging from 500 to $2,150 \mathrm{~m}$ above see level (van Slageren 1994). Communities with a single representative Aegilops are rare, as usually more than one species occurs in the same community. Aegilops species occur in both the Mediterranean and IranoTuranian regions (Hedge et al. 2002). Transcaucasia is the proposed centre of origin for this genus, with suggestions that its centre of diversity follows the Fertile Crescent arc in western Asia (van Slageren 1994). Many Aegilops species are known to occur in Armenia, including Ae. umbellulata Zhuk., Ae. cylindrica Host, Ae. tauschii Coss. [= Ae. squarrosa auct. non L.], Ae. triuncialis L., Ae. neglecta Req. ex Bertol., [= Ae. triaristata Willd.], Ae. mutica Boiss. [=Amblyopyrum muticum (Boiss.) Eig var. muticum], Ae. biuncialis Vis., Ae. columnaris Zhuk. and Ae. crassa Boiss. [= Ae. trivialis Zhuk.].

Studies on interspecific diversity, distribution and in situ conservation of the genetic resources of Aegilops species have been undertaken in Armenia (Harutyunyan et al. 2008). Based on these studies, conservation activities were initiated and the Erebuni State Reserve has been specifically established for the conservation of wild relatives of cereal crops, including the Aegilops species Ae. triuncialis, Ae. cylindrica, Ae. tauschii and A. columnaris.
Aegilops populations are also found in other protected areas such as Khosrov State Reserve and Goravan Sandlands Reservation. Since 1981, a collection of Aegilops germplasm composed of 1,715 accessions has been maintained at the Plant Genetic Resource and Breeding Laboratory of Armenian State Agrarian University.

Despite these actions, the status of these wild relatives and population trends remain undocumented. The International Union for Conservation of Nature (IUCN) Red List offers an authoritative and objective mechanism for assessing the conservation status of wild plants and animals (Rodrigues et al. 2006), which can also be applied at the regional and national levels (IUCN 2003). The conservation status of the wild species are determined using the new IUCN categories and criteria, which consist of eight categories, namely Extinct (EX), Extinct in the Wild (EW), Regionally Extinct (RE), Critically endangered (CR), Endangered (EN) and Vulnerable (VU), Near Threatened (NT) and Least Concern (LC). Of these, CE, EN and VU are known as categories of threats (IUCN 2001). Each of the threat categories are then defined by five criteria denoted by letters A-E as well as sub-criteria denoted by numbers and lower case letters, based on population sizes, fragmentation and population viability analysis. IUCN's Red List system is increasingly being used by countries to develop their own national Red Listings. Milner-Gulland et al. (2006) successfully tested the applicability of the IUCN criteria at the sub-regional level in five Central Asian Countries on 163 vertebrates. Magos Brehm et al. (2008) also showed that IUCN criteria worked well at the national level for Portuguese crop wild relatives. The Red List process is an important step in developing conservation strategies and formulating conservation policies. In many countries of the former Soviet Union, Red Data Books are used to define their countries' conservation policies (Milner-Gulland et al. 2006). However, the criteria by which species were listed vary between republics, making any comparison between them extremely difficult. At the global level, the Red List has made significant progress in the evaluation of conservation status of several groups of organisms (http://www.iucnredlist.org) and is considered a headline indicator for monitoring progress towards the 2010 target of reducing biodiversity loss (Secretariat of the Convention on Biological Diversity 2006). 
The aims of this study are to determine the geographical and ecological distribution of nine Aegilops species in Armenia and to assess the IUCN Red List status of these species. The study was carried out as part of a global project "In situ Conservation of Crop Wild Relatives through Enhanced Information Management and Field Application", funded under United Nations Environment Programme/Global Environment Facility (UNEP/GEF).

\section{Materials and methods}

\section{Ecogeographic survey}

An ecogeographic survey of nine Aegilops species (Table 1) was undertaken within the Republic of Armenia following the methodology of Maxted et al. (1995). The first step involved collating information on the taxonomy, occurrence and distribution of the Aegilops spp. by reviewing the literature and examining herbaria at the Institute of Botany of the National Academy of Sciences, Plant Genetic Resource Laboratory of Armenian State Agrarian University, the Department of Botany of Yerevan State University and seed bank records at Plant Genetic Resource Laboratory of Armenian State Agrarian University. Literature sources consulted include 'Flora of Armenia: Poaceae' (Gandilyan and Nazarova 2010), van Slageren (1994) and Gabrielian and Zohary (2004), which provide the best current knowledge of Aegilops in Armenia. In addition, local botanists from the Department of Higher Plant Taxonomy and Geography at Institute of Botany, were consulted. The information collected was used to draft the preliminary distribution of Aegilops species, as well as to plan the timetable and routes for field studies.

\section{Field work}

Extensive field surveys were conducted in Armenia (Table 2) during two consecutive years (2006 and 2007) in the summer months (May to August) when Aegilops species are at the spike-bearing stage and identification is easy. Slight adjustments were made for individual species and altitudes in different regions. For example Ae. crassa is known to flower earlier and visits were scheduled in May while sites located at relatively high altitudes (1,500-2,000 m) were visited later in the season (July and August). Ae. umbellulata is reported from the border of Ordubad region in Nakhichevan Autonomous Republic (Azerbaijan) and the Meghri region of Syunik marz. It was not possible to access these sites from Armenia and the species was therefore not included in the field surveys.

The data collected during field surveys included latitude, longitude and altitude (collected using a GPS), description of location including administrative unit and nearest settlement, conservation status of the area, average density (number of plants per unit surface), approximate area occupied by each subpopulation, plant community, current and potential threats, growth stage and soil characteristics. If the species could not be properly identified, a specimen was taken for determination at the herbarium. Where possible, seeds (in the form of spikes) were collected for ex situ conservation at Plant Genetic Resource Laboratory of Armenian State Agrarian University as a complementary measure. Collection was undertaken at random in order to capture the maximum genetic diversity of the population and not to endanger the natural population, following the guidance of the IUCN technical guidelines on the management of ex situ populations (IUCN 2002).

\section{Red List assessment}

The IUCN Red List-Categories and Criteria version 3.1 (IUCN 2001) was used to determine the Red List status of the Aegilops species in Armenia and threat category was then adjusted using the guidelines for applying IUCN Red List categories at the regional level (IUCN 2003). The calculation of area of occupancy (AOO) of a species can be quite subjective depending on the grid size used to calculate the area. In this study, calculations were made using a grid size of $4 \mathrm{~km}^{2}$ except where otherwise indicated. Certain Aegilops species are known to have small populations and a limited range in Armenia-for these species, a grid size of $1 \mathrm{~km}^{2}$ was used.

\section{Results}

Herbarium and seed collection survey

The herbaria and seed bank collections of Aegilops species studied are presented in Table 3. These 


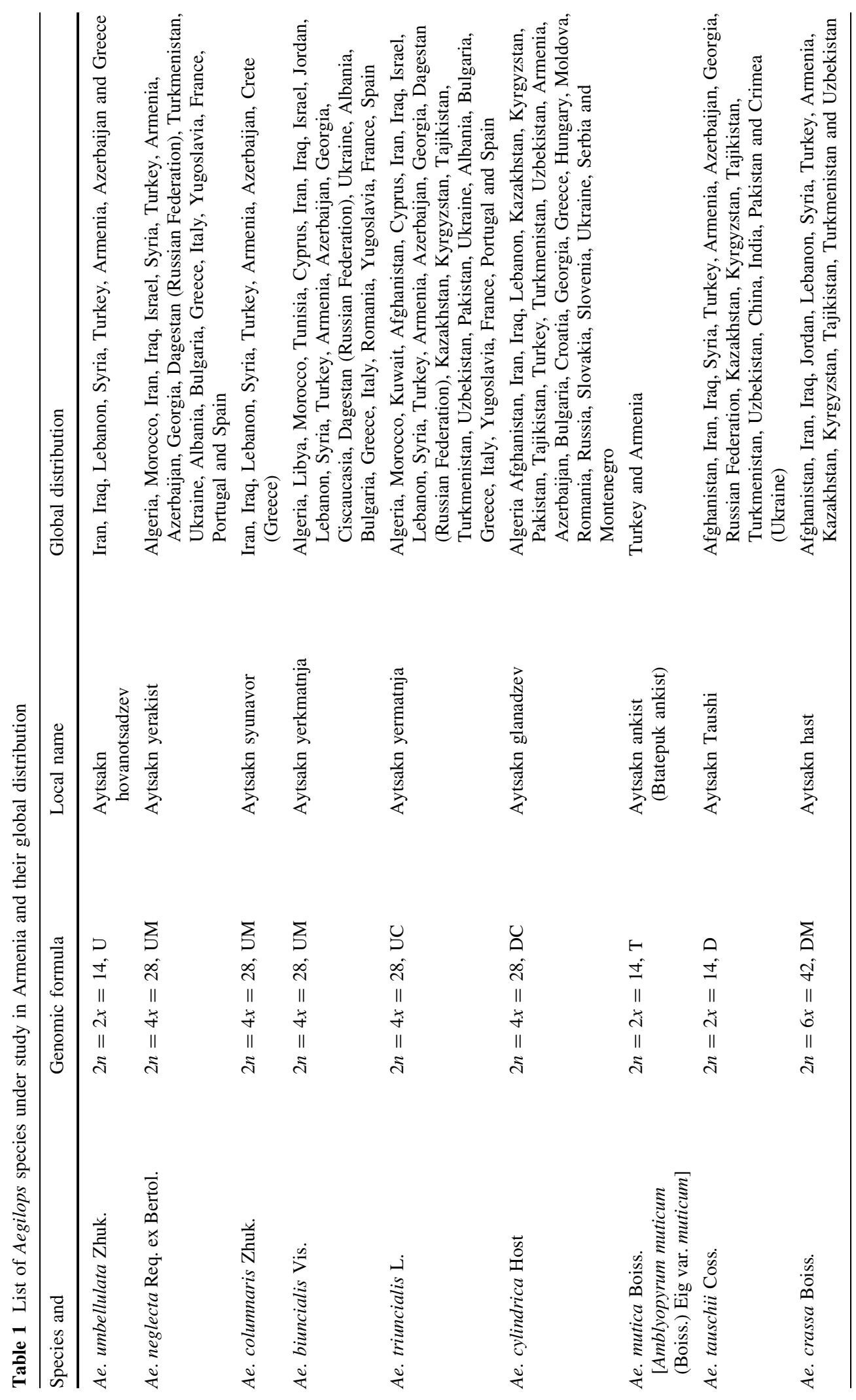


Table 2 Ecogeographic surveys: list of Aegilops species known to occur at sites visited

\begin{tabular}{|c|c|c|}
\hline Site & $\begin{array}{l}\text { Administrative } \\
\text { subunit (marz) }\end{array}$ & $\begin{array}{l}\text { Aegilops species known } \\
\text { and likely to occur }\end{array}$ \\
\hline $\begin{array}{l}\text { Near Shorbulagh (Mushavan) village } \\
\text { including Erebuni State Reserve }\end{array}$ & Kotayk, Yerevan & $\begin{array}{l}\text { Aegilops triuncialis } \\
\text { Ae. cylindrica } \\
\text { Ae. tauschii } \\
\text { Ae. columnaris } \\
\text { Ae. mutica** }\end{array}$ \\
\hline $\begin{array}{l}\text { Near village Akunk, from } \\
\text { Dzitankov to Maralik }\end{array}$ & Aragatsotn, Shirak & $\begin{array}{l}\text { Ae. cylindrica } \\
\text { Ae. tauschii } \\
\text { Ae. triuncialis }\end{array}$ \\
\hline Akunk-Zar, Kaputan-Kotayk & Kotayk & $\begin{array}{l}\text { Ae. cylindrica } \\
\text { Ae. triuncialis } \\
\text { Ae. tauschii }\end{array}$ \\
\hline $\begin{array}{l}\text { Shaghap, Lanchanist, Urtsadzor, } \\
\text { including Khosrov State Reserve }\end{array}$ & Ararat & $\begin{array}{l}\text { Ae. tauschii } \\
\text { Ae. columnaris } \\
\text { Ae. cylindrica } \\
\text { Ae. triuncialis } \\
\text { Ae. biuncialis }\end{array}$ \\
\hline $\begin{array}{l}\text { Hrazdan river gorge, Kanaker, } \\
\text { Avan, Garni, Geghard }\end{array}$ & Yerevan, Kotayk & $\begin{array}{l}\text { Ae. crassa } \\
\text { Ae. tauschii } \\
\text { Ae. cylindrica } \\
\text { Ae. columnaris } \\
\text { Ae. triuncialis }\end{array}$ \\
\hline Talin, Spitak towns & Lori, Aragatsotn & $\begin{array}{l}\text { Ae. cylindrica } \\
\text { Ae. triuncialis } \\
\text { Ae. tauschii }\end{array}$ \\
\hline $\begin{array}{l}\text { Vayk, Goris, Kapan, Meghri towns, } \\
\text { Khndzoresk v., Shikahogh State Reserve }\end{array}$ & Vayots Dzor, Syunik & $\begin{array}{l}\text { Ae. tauschii } \\
\text { Ae. neglecta } \\
\text { Ae. umbellulata } \\
\text { Ae. cylindrica } \\
\text { Ae. columnaris } \\
\text { Ae. triuncialis }\end{array}$ \\
\hline Byurakan and Dzorap villages & Aragatsotn & $\begin{array}{l}\text { Ae. tauschii } \\
\text { Ae. triuncialis } \\
\text { Ae. cylindrica }\end{array}$ \\
\hline
\end{tabular}

** Not recorded during field survey were examined and their passport data analyzed (see Table 3).

Ecogeographic survey

Table 2 shows that out of the nine Aegilops species, six species, namely Ae. cylindrica, Ae. tauschii, Ae. triuncialis, Ae. neglecta, Ae. biuncialis and Ae. columnaris, were identified during the field surveys. A. mutica was not seen during the field surveys, but was found by a team from the Institute of Botany (E. A. Nazarova 


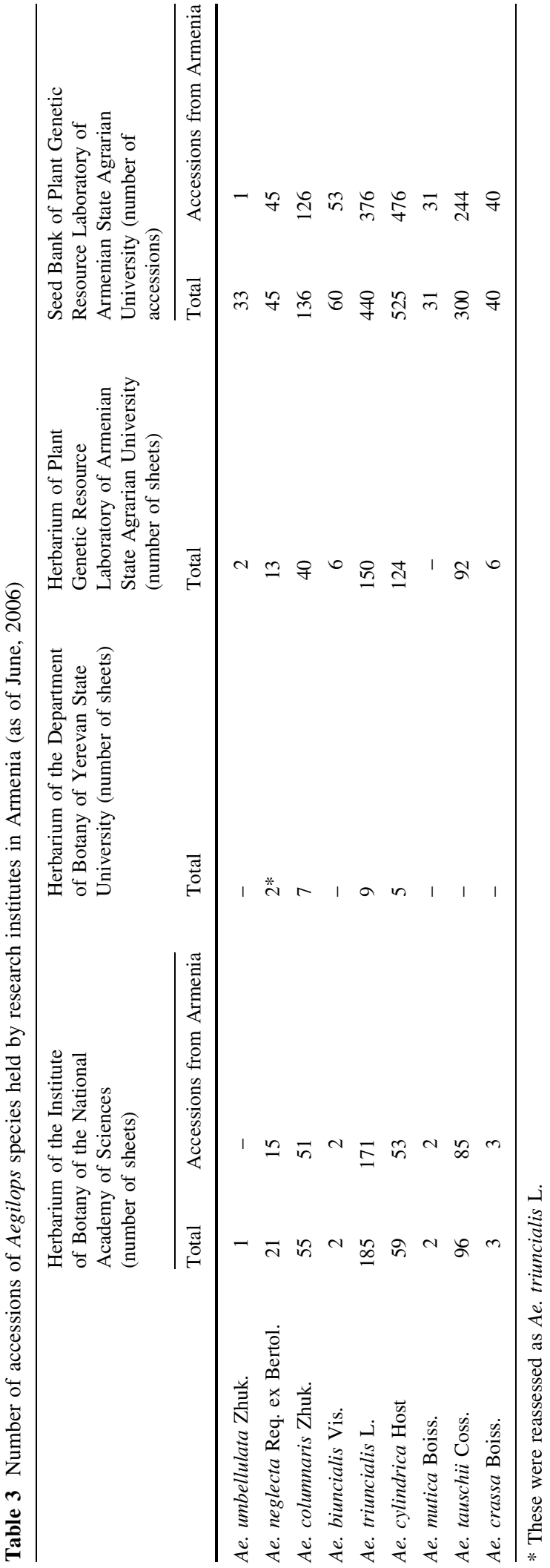

personal communication) in 2007. Ae. crassa, has not been seen in its historical and expected habitats since 2005, when it was recorded in Hrazdan River Gorge.

The field survey provided ample data on the ecology of Aegilops populations, which were not available from the herbaria. The ecogeographic data gathered from the herbaria and field survey were organized into an ecogeographic conspectus, defined by Maxted et al. (1995) as a formal summary of the available taxonomic, geographic and ecological information of the target taxon (Table 4). A summary of the ecogeographic conspectus is given below for each of the nine Aegilops species under study.

\section{Ae. umbellulata Zhuk.}

The taxon that occurs in Armenia is Ae. umbellulata Zhuk. ssp. transcaucasica Dorof. et Migush. Here, a new variety with black spikes (Ae. umbellulata Zhuk. var. tuluni Gandil. et Harut.) (Gandilyan and Harutunyan 1987) has been described. This species has a global distribution (Table 1), but is known from only one subpopulation (using the definition of IUCN 2001) (Fig. 1; Table 4). This taxon is threatened by land privatization, uncontrolled grazing and hay harvest; habitat quality is in continuous decline. It could meet the sub-criteria B1 and B2 for Critically Endangered. However, the only population of Ae. umbellulata in Armenia is located in a site that is difficult to access and the current status of the population is unknown (Data Deficient). The last accessions were recorded in 1988 by Armenian botanists.

Ae. neglecta Req. ex Bertol.

Ae. neglecta has a wide distribution, spreading across Central Asia, Europe and North Africa (Table 1). In Armenia, it is known from only two locations (Fig. 2; Table 4). Given the many threats facing this taxon and its restricted distribution (Table 4), the conservation status in Armenia is Endangered (EN), under criteria B1, 2. As a result of ecogeographic surveys, continuing decline was recorded in quality of habitat as a result of road construction, fire, grazing, urbanization and mining activities. The in-country subpopulation crosses the Azerbaijani border, however no information is available about foreign populations. 


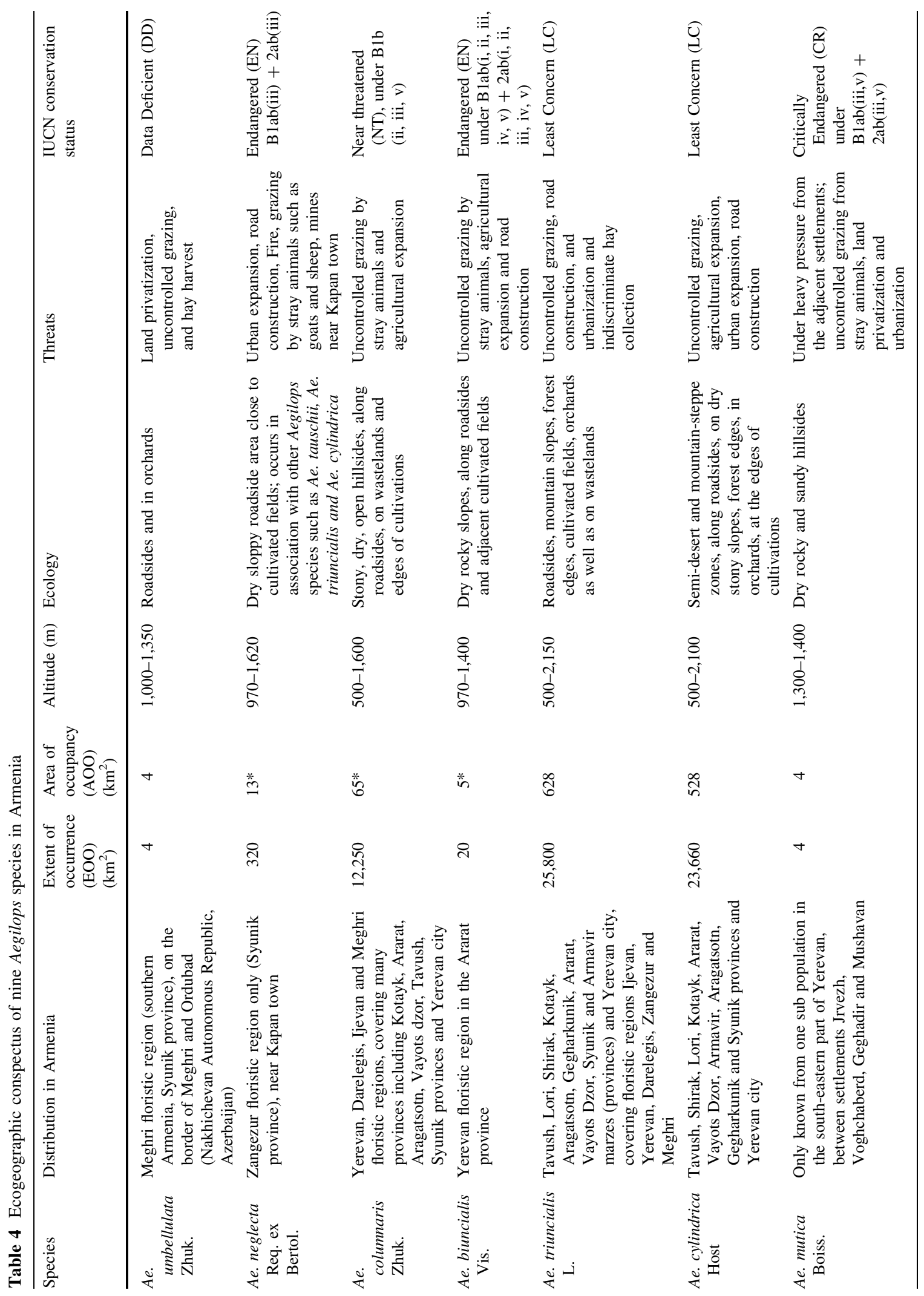




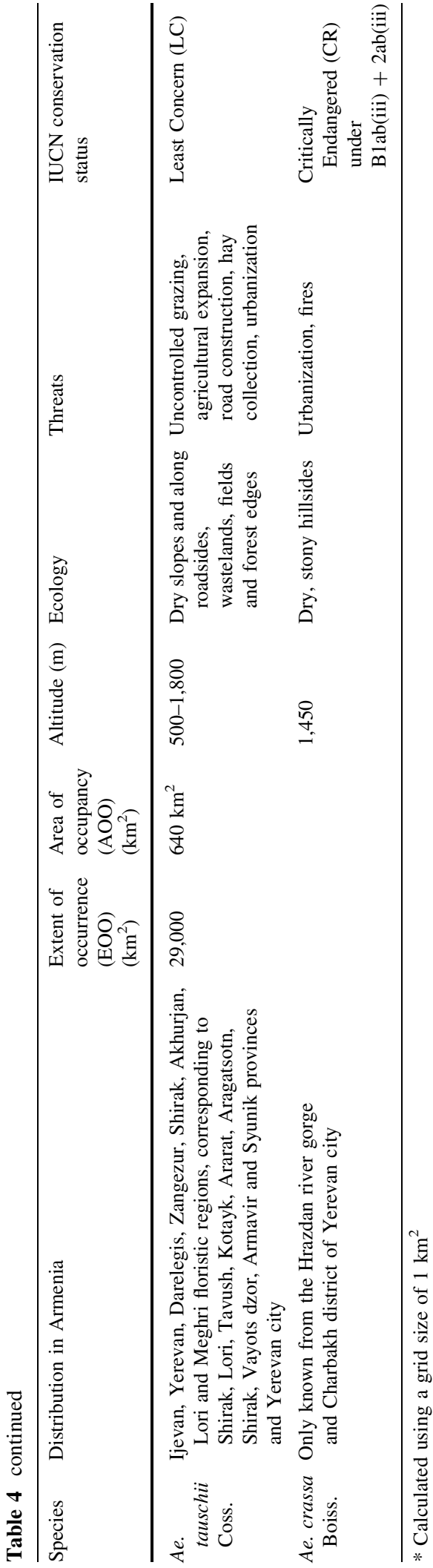

Ae. columnaris Zhuk.

Two varieties of Ae. columnaris were distinguished by Zhukovski (1928): var. glabriuscula Zhuk., and var. columnaris Zhuk. In the Armenian populations, the taxon exhibits eight different forms based on the colour of spike and awns, and texture of glumes. Natural hybrids of Ae. columnaris $\times$ Ae. biuncialis, Ae. columnaris $\times$ Ae. triuncialis and Ae. columnaris $\times$ Ae. cylindrica are common. Ae. columnaris is distributed across several countries (Table 1) and is also widely distributed across Armenia (Fig. 1; Table 4). The conservation status of Ae. columnaris is classified as Near Threatened under B1b (ii, iii, v), although the species could be considered threatened as it meets sub-criteria B1 and B2 based on Extent of Occurrence (EOO) and AOO parameters of less than 20,000 and $2,000 \mathrm{~km}^{2}$ respectively. However, it was reported from 11 locations, which is above the threshold for Vulnerable. There is a continuing decline in the area, extent and quality of habitat due to threats (Table 4; Fig. 1) and there is no information about exchange of propagules with subpopulations from neighboring regions.

\section{Ae. biuncialis Vis.}

Zhukovski (1928) distinguished two varieties of Ae. biuncialis: var. vulgaris Zhuk. and var. velutina Zhuk. Only the latter variety occurs in Armenia, however, six forms were suggested for the populations that occur in Armenia within var. velutina Zhuk. based on the color of spike and awns, and texture of glumes. As a bearer of the $\mathrm{C}$ genome, it is resistant to leaf rust. Like Ae. neglecta, Ae. biuncialis has a wide distribution, spreading across central Asia, Europe and North Africa (Table 1), but has a very restricted distribution (EOO and AOO) in Armenia (Fig 3; Table 4). The taxon meets subcriteria B1 and B2 for Critically Endangered; it is known from two locations from a single subpopulation in Ararat province (Fig. 3). The taxon was earlier reported from Syunik province, with two small subpopulations near Goris town and Lehvaz village. During recent years these subpopulations have not been found, providing evidence of continuing decline in EOO, AOO, number of locations and subpopulations, and number of mature individuals as well as in the quality of habitat as a result of threats (Table 4). Exchange of propagules with neighboring 
Fig. 1 Distribution of Aegilops columnaris, Ae. triuncialis, Ae. umbellulata in Armenia

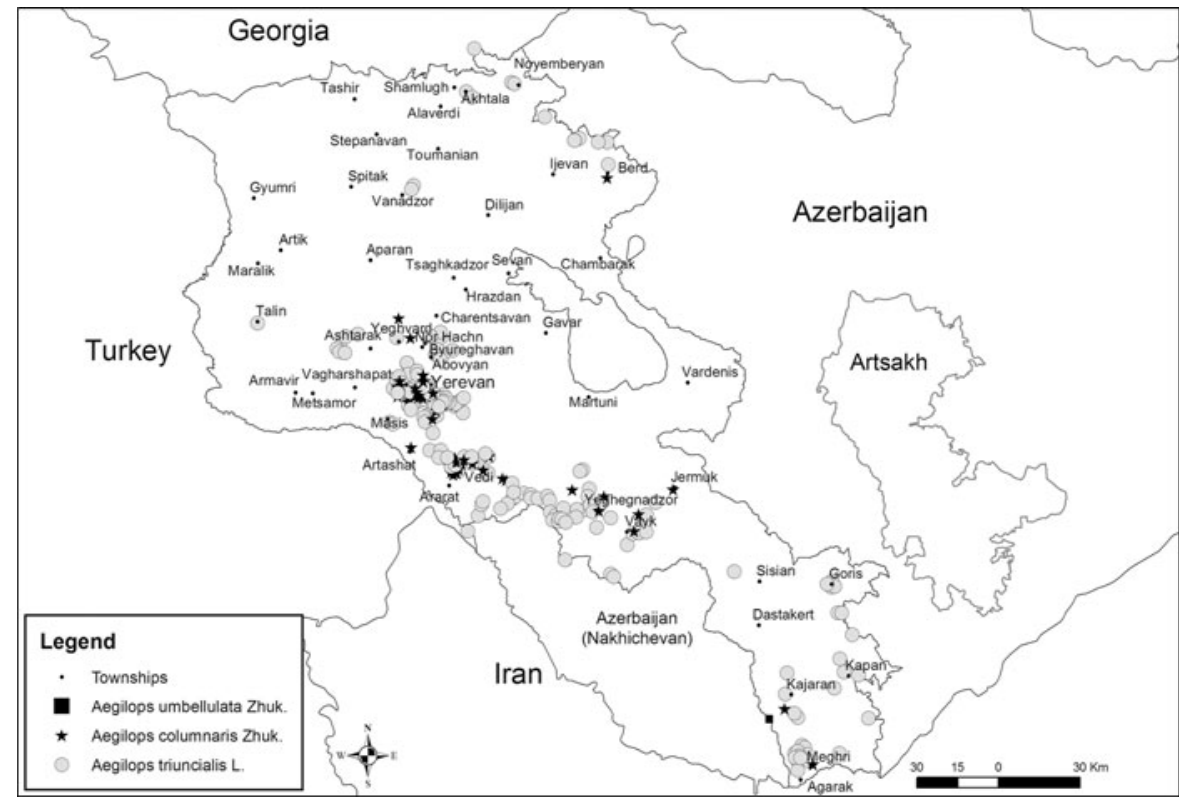

Fig. 2 Distribution of Aegilops crassa, Ae. neglecta, Ae. cylindrica in Armenia

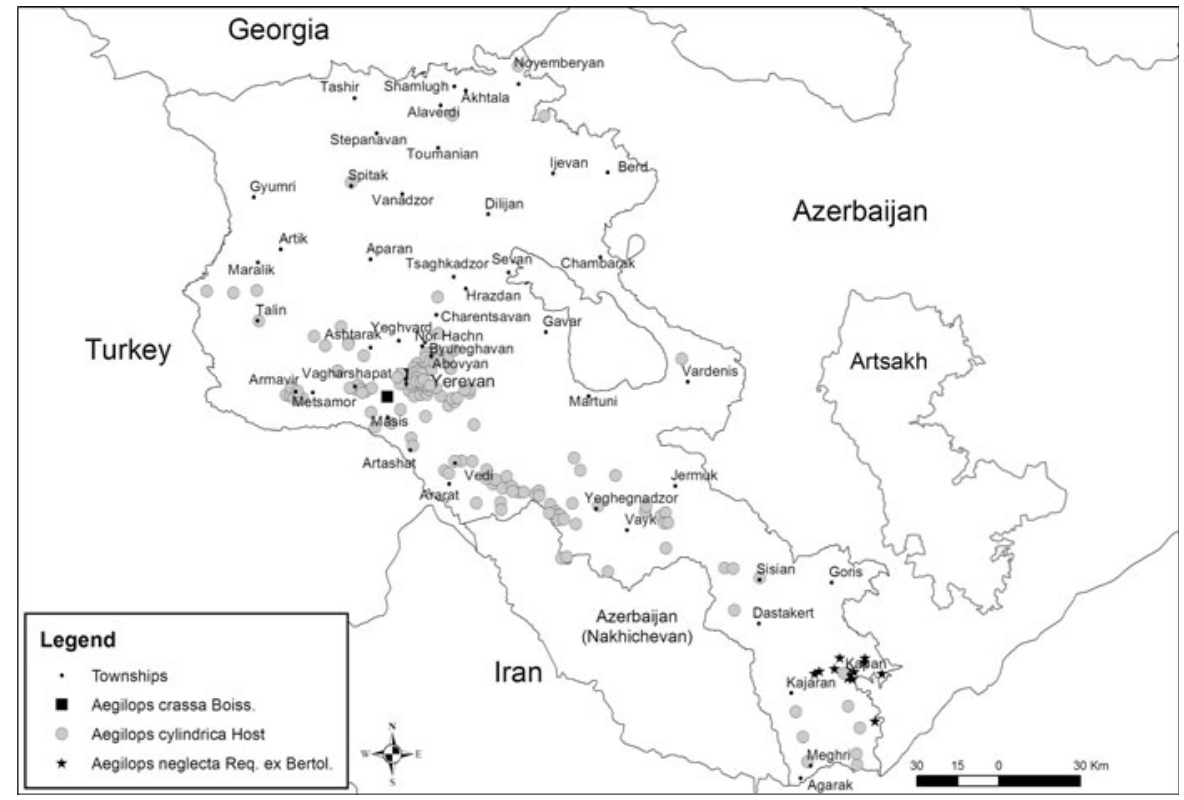

countries is not likely, since the Armenian subpopulation is located far from the border. Hence, the original assessment is unchanged-the taxon is listed in Armenia as Endangered.

\section{Ae. triuncialis L.}

Ae. triuncialis is a polymorphic species: 17 different forms have been identified within the subsp. triuncialis (=ssp. typica Zhuk.) and subsp. persica (Boiss.) Zhuk. within the Armenian subpopulation (Harutyunyan 1991). Unlike other Aegilops species, A. triuncialis is prone to fungus dust-brand (Ustilago passerinii Fisch). Along with infested individuals, resistant individuals were also found in the same phytocenoses. These individuals can be used in breeding resistant wheat cultivars. Ae. triuncialis has a wide geographical range extending from 
Fig. 3 Distribution of Aegilops biuncialis, Ae. tauschii, Ae. mutica in Armenia

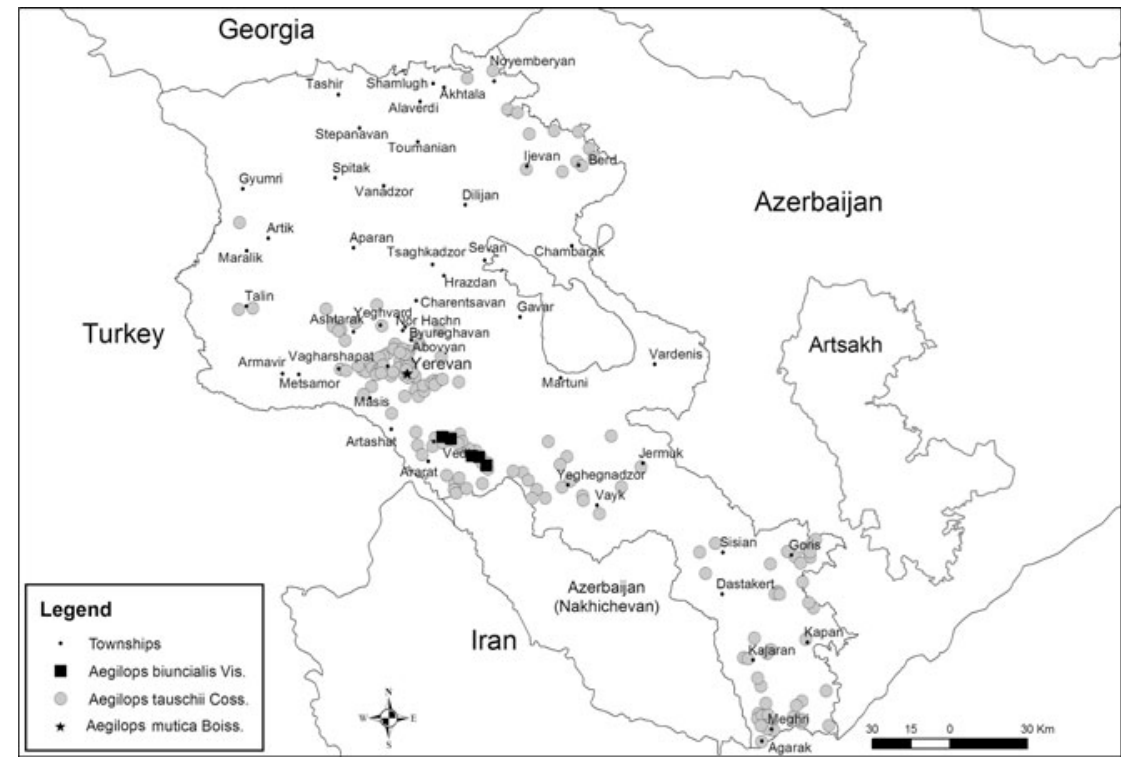

Central Asia to Europe and across the Mediterranean to North Africa (Table 1). In Armenia, the species is common and classified as Least Concern. Although the AOO of the taxon is $<2,000 \mathrm{~km}^{2}$, the number of locations is more than ten (Table 4) and it is rather uniformly distributed along the southern and southwestern borders of Armenia (Fig. 1). This subpopulation is rather stable, although the taxon is known to be under threat (Table 4).

\section{Ae. cylindrica Host}

This species is known from the countries of Central Asia and Eastern Europe (Table 1). In Armenia, it is present in all administrative sub-units (Fig. 2; Table 4) and is regarded as a common weed. Although the AOO of the taxon is less than $2,000 \mathrm{~km}^{2}$, the number of locations is more than 20. It is considered to be a species of Least Concern in Armenia, as this annual weed is widely spread throughout the country, its distribution can hardly be qualified as fragmented (Fig. 2) and there is no continued decline in any of its parameters. Nevertheless, during field studies some threats were identified (Table 4).

\section{Ae. mutica Boiss.}

According to Hammer (1980b), Ae. mutica is known from two varieties namely var. mutica and var. loliacea (Jaub. et Sp.) Eig, and each variety has four different forms. Compared to other Aegilops species, Ae. mutica has a restricted distribution and is only known in Turkey and Armenia. In Armenia, it is only known from one subpopulation in the south-eastern part of Yerevan (Fig. 3) (Gandilyan 1975). Given its restricted distribution (Table 4), drastic decline in the population size (E. A. Nazarova personal communication) and continuing decline in area, extent and quality of habitat, it is Critically Endangered under B1ab(iii,v) $+2 a b(i i i, v)$. The population in Armenia is isolated from those in neighboring countries. This taxon is a bearer of the B genome of hexaploid wheat. It is listed in Red Data Book of Armenia (Gabrielian 1988).

\section{Ae. tauschii Coss.}

In Armenia, three subspecies have been reported as synonyms of Ae. tauschii in the USDA's GRIN database (http://www.ars-grin.gov/cgi-bin/npgs/html/taxon. pl?1550). These include subsp. meyeri (Griseb.) Tzvel., subsp. strangulata (Eig) Tzvel. and subsp. tauschii. The subspecies meyeri is a mesophilous form typical of Ijevan and less frequent in the Meghri floristic region. Five forms were distinguished within this subspecies. The distribution range of subspecies strangulata, with more stout spikes, extends to the Yerevan, Zangezur and Meghri floristic regions. Three 
Table 5 Summary of threat assessment of nine Aegilops species in Armenia

\begin{tabular}{|c|c|c|c|c|c|c|}
\hline \multirow[t]{2}{*}{ Species } & \multicolumn{3}{|l|}{ Threatened category } & \multirow{2}{*}{$\begin{array}{l}\text { Near } \\
\text { threatened } \\
\text { NT }\end{array}$} & \multirow{2}{*}{$\begin{array}{l}\text { Least } \\
\text { concern } \\
\text { LC }\end{array}$} & \multirow{2}{*}{$\begin{array}{l}\text { Data } \\
\text { deficient } \\
\text { DD }\end{array}$} \\
\hline & $\mathrm{CR}$ & EN & VU & & & \\
\hline Ae. umbellulata Zhuk. & & & & & & DD \\
\hline Ae. neglecta Req. ex Bertol. & & B1ab(iii) + 2ab(iii) & & & & \\
\hline Ae. columnaris Zhuk. & & & & B1b(ii, iii, v) & & \\
\hline Ae. biuncialis Vis. & & $\begin{array}{c}\text { B1ab(i, ii, iii, iv, v) + } \\
\text { 2ab(i, ii, iii, iv, v) }\end{array}$ & & & & \\
\hline Ae. triuncialis $\mathrm{L}$. & & & & & $\mathrm{LC}$ & \\
\hline Ae. cylindrica Host & & & & & $\mathrm{LC}$ & \\
\hline Ae. mutica Boiss. & B1ab (iii, v) + 2ab(iii, v) & & & & & \\
\hline Ae. tauschii Coss. & & & & & $\mathrm{LC}$ & \\
\hline Ae. crassa Boiss. & B1ab (iii) + 2ab(iii) & & & & & \\
\hline
\end{tabular}

$C R$ critically endangered, $E N$ endangered, $V U$ vulnerable, $N T$ near threatened, $L C$ least concern, $D D$ data deficient

forms were described within this subspecies. Subspecies tauschii is mainly known from the Yerevan floristic region and has seven different forms, described based on the color of spikes and awns, and texture of glumes (Harutyunyan 1991). For the purposes of this paper, a Red List assessment was conducted at the species level. Ae. tauschii is considered to be the donor of hexaploid wheat's D genome.

The species is common in Central and West Asia (Table 1), and is fairly well distributed throughout central and southern Armenia (Fig. 3.). As it does not show signs of decline, it is regarded as of Least Concern. The number of locations is more than ten, the taxon is not experiencing extreme fluctuations and there is no continued decline in any of parameters of interest. Nevertheless, during field studies some threats to the populations were identified (Table 4).

\section{Ae. crassa Boiss.}

The taxon is of practical and scientific value, as it is the bearer of the D genome of hexaploid wheat. It easily crosses with soft wheat. The distribution of Ae. crassa is not well known. According to Clayton et al. (2006), it is a species of the temperate Asia region covering Central Asia, the Caucasus, and western Asia (Table 1). In Armenia, the taxon has been reported from the Charbakh district of highly urbanized Yerevan City and Hrazdan River Canyon (Fig. 2), based on herbarium data. Unfortunately, during last 3 years, the taxon has not been seen in its reported and expected habitats. As a precautionary approach, this taxon is maintained as Critically Endangered under B1ab(iii) + 2ab(iii).

\section{Discussion}

Of the nine Aegilops species studied, only four are in the Threatened category (Table 5). Of these, Ae. mutica and Ae. crassa are Critically Endangered in Armenia, and should receive priority in conservation activities to safeguard them. The necessity of conserving Ae. mutica was also stressed by other authors (Hammer 1980a) It is fortunate that accessions of these two species exist in genebanks (Table 3). Uncontrolled grazing and hay harvest are among the major threats to the populations of Aegilops in Armenia identified during field surveys. Their hard spikes make Aegilops poor fodder plants, however in early spring, when shoots are soft and fleshy, they are eaten by livestock. Although Aegilops species prefer somewhat disturbed environments and are common along roadsides, the consequences of road construction, including polluted environment, frequent fires and trampling have negatively impacted these populations. Land privatization, which started in Armenia at the end of the twentieth century, and subsequent agricultural development on these lands, is also impacting the quality of habitat and populations of Aegilops species. 
Large subpopulations of Ae. columnaris, Ae. cylindrica, Ae. tauschii and Ae. triuncialis extend to highly urbanized Yerevan city, (Figs. 1, 2, 3), which is contributing to the deterioration of their habitat. In the case of Ae. crassa, the only population was located in Yerevan city, which may have resulted in the apparent extinction of populations in the wild.

The regional assessment of Aegilops species was made under criterion B (restricted geographic range). Assessment under A (population reduction) was not possible due to the absence of quantitative information related to population decline. Although efforts were made in this study to estimate the species' population size, no historical data were available to quantify the trend. Population studies (especially data related to population size estimates) are very few in Armenia. Criteria C and D, based on population size, were also not applicable because the size of the smallest population of these annual grasses is more than 10,000. Quantitative analysis (criterion E) was not conducted for any of the species.

When assessing under criterion $\mathrm{B}$, priority was given to sub-criterion B1. Most distribution points were derived from herbarium passport data. It is important to note that herbarium information should be treated with caution. Some records are old and difficulties were encountered in handling outdated information, particularly old names of settlements and administrative sub-units. In addition, only a few location descriptions were accompanied by GPS readings. The distribution maps were produced based on the best available information on possible collection sites in the passport data. It should also be noted that, due to the small size of Armenia itself $\left(29,000 \mathrm{~km}^{2}\right)$, EOO and AOO for the in-country subpopulations qualify for the Threatened category under sub-criteria B1 and B2 for most plants. Therefore, during the assessment, emphasis was on accurate application of sub-criteria $a$ and $b$. As a result of ambiguity in identifying "severe fragmentation" (Magos Brehm et al. 2008), its application was also restricted in the current study and assessment was mainly based on the number of locations. Sub-criterion c (extreme fluctuations) was also rarely applied since limited resources prevented regular monitoring of populations and historical data is therefore lacking.

The assessment of conservation status is an important initial step in conservation planning, which helps to identify priority actions for safeguarding threatened species. While the status of some of the Aegilops species in Armenia has been well documented, there is a dearth of information from neighboring countries to better understand the species' regional threat status. The current status of the Aegilops populations in neighboring countries (Iran, Turkey, Georgia and Azerbaijan) is unknown. The unavailability of information from neighboring countries was cited as a limiting factor in other Red List regional assessments (Magos Brehm et al. 2008). During the Soviet era, Armenian botanists actively conducted surveys in the Nakhichevan Autonomous Republic (Azerbaijan). There have been no such surveys after the collapse of the Soviet Union and the current status of Aegilops in Nakhichevan is unknown. Armenian populations of Ae. biuncialis and Ae. mutica are located far from the border and exchange of propagules with neighboring countries is unlikely. The original assessment of Ae. neglecta, and Ae. columnaris will not have changed since no information is available about their populations in neighboring countries.

There is an urgent need for extensive field surveys of Ae. umbellulata in Armenia well as in Turkey, Azerbaijan (Nakhichevan) and Greece. The four threatened species Ae. neglecta, Ae. biuncialis, Ae. mutica and Ae. crassa should be included in the new Red Data Book of Armenia currently under preparation. In addition, there is a need to conduct regular surveys in the historical habitats of Ae. crassa as well as to develop reintroduction (benign introduction) programmes. Although Ae. tauschii is of least concern, its wild populations in Erebuni Reserve should provide adequate protection to this species, along with other wild relatives of wheat (genus Triticum). It is important however, that these species be included in the management plan of the protected area currently under development through the UNEP/GEF-supported project on crop wild relatives in Armenia being implemented by Bioversity International.

In conclusion, we note that there has been a dramatic decline in the genetic resources of Aegilops during recent years in Armenia as a result of adverse human impacts such as agricultural expansion, uncontrolled grazing, road development and urbanization. In some cases, these threats are causing the extinction of representative Aegilops populations. It should be borne in mind that each species, variety and 
ecotype carries potentially valuable genetic information that can improve the adaptability and productivity of cultivated wheat varieties. Therefore, efforts should be made to conserve the genetic diversity of this genus both in situ and ex situ. It is further recommended that ex situ material conserved in genebanks be used to restore lost populations in their areas of origin.

Acknowledgments We thank Dr. E. A. Nazarova and colleagues from the department of Higher Plant Taxonomy and Geography, Institute of Botany of the National Academy of Sciences for their help and guidance. We would also like to acknowledge assistance of Hayk Yeritsyan from Geocom LTD. in the preparation of GIS maps. We thank Imke Thormann (Bioversity International) for helping with the review of the manuscript.

Open Access This article is distributed under the terms of the Creative Commons Attribution Noncommercial License which permits any noncommercial use, distribution, and reproduction in any medium, provided the original author(s) and source are credited.

\section{References}

Clayton WD, Harman KT, Williamson H (2006 onwards) GrassBase- the online world grass flora. http://www.kew. org/data/grasses-db.html. Accessed 23 Oct 2008

Dvorak J, Zhang HB (1990) Variations in repeated nucleotide sequences shed light on the phylogeny on the wheat B and G genomes. Proc Nat Acad Sci 87:9644-9649

Gabrielian E Ts (ed) (1988) Red data book of Armenia: plants. Yerevan, p 284 (in Russian)

Gabrielian E, Zohary D (2004) Wild relatives of food crops native to Armenia and Nakhichevan. Flora Mediter 14:5-80

Gandilyan PA (1975) Aegilops mutica Boiss. in Armenia. Trudy Prikl Bot Gen Sel Leningrad 54(1):245-246

Gandilyan PA, Harutunyan MG (1987) New information about Aegilops umbellulata Zhuk. in Subcaucasus. Biol J Armenia 40(6):475-478 (in Russian)

Gandilyan PA, Nazarova EA (2010) Aegilops, Amblyopyrum. Flora of Armenia. In: Takhtajan A (ed) vol 11. (in press)

Hammer K (1980a) Zur Taxonomie und Nomenklatur der Gattung Aegilops L. Feddes Rep 91:225-258

Hammer K (1980b) Vorarbeiten zur monographischen Darstellung von Wildpflanzensortimenten: Aegilops L. Kulturpflanze 28: 33-180
Harlan JR, de Wet JMJ (1971) Towards a rational classification of cultivated plants. Taxon 20:509-517

Harutyunyan MG (1991) Biological-ecological characteristics of Aegilops genus in the Republic of Armenia. $\mathrm{PhD}$ thesis, Yerevan, p 152 (in Russian)

Harutyunyan M, Avagyan A, Hovhannisyan M (2008) Impoverishment of the gene pool of the genus Aegilops L., in Armenia. In: Maxted N, Ford-Lloyd BV, Kell SP, Iriondo J, Dulloo E, Turok J (eds) Crop wild relative conservation and use. CAB International, Wallingford, pp 309-331

Hedge SG, Valkoun J, Waines JG (2002) Genetic diversity in wild and weedy Aegilops, Amblyopyrum and Secale species-a preliminary survey. Crop Sci 42:608-614

IUCN (2001) IUCN Red List categories and criteria: version 3.1. IUCN, Species Survival Commission. IUCN, Gland, Switzerland and Cambridge, UK, pp ii +30

IUCN (2002) IUCN technical guidelines on the management of ex situ populations for conservation, approved at the 14th Meeting of the Programme Committee of Council, Gland Switzerland, 10 December 2002

IUCN (2003) Guidelines for application of IUCN Red List criteria at regional levels: version 3.0. IUCN Species Survival Commission. IUCN, Gland, Switzerland and Cambridge, UK, pp ii +26

Magos Brehm J, Mitchell M, Maxted N, Ford-Lloyd BV, Martins-Loução MA (2008) IUCN Red Listing of crop wild relatives: is a National approach as difficult as some think? In: Maxted N, Ford-Lloyd BV, Kell SP, Iriondo J, Dulloo E, Turok J (eds) Crop wild relative conservation and use. CAB International, Wallingford, pp 211-242

Maxted N, van Slageren MW, Rihan JR (1995) Ecogeographic surveys. In: Guarino L, Ramanatha Rao V, Reid R (eds) Collecting plant genetic diversity technical guidelines. CAB International, Wallingford International Plant Genetic Resources Institute, Rome, Italy, Chapt 14, pp 255-287

Milner-Gulland EJ, Kreuzberg-Mukhina E, Grebot B, Ling S, Bykova E, Abdusalamov I, Bekenov A, Gä Rdenfors U, Hilton-Taylor C, Salnikov V, Stogova L (2006) Application of the IUCN Red Listing criteria at the regional and national levels: a case study from Central Asia. Biodivers Conserv 15:1873-1886

Rodrigues ASL, Pilgrim JD, Lamoreux JF, Hoffmann M, Brooks TM (2006) The value of the IUCN Red list for conservation. Trends Ecol Evol 21(2):71-76

Secretariat of the Convention on Biological Diversity (2006) Global biodiversity outlook 2. Montreal, pp $81+$ vii

van Slageren MW (1994) Wild wheats: a monograph of Aegilops L. and Amblyopyrum (Jaub. \& Spach) Eig (Poaceae), Wageningen, p 512

Zhukovski PM (1928) Critical-systematic revision of species from genus Aegilops. Trudy Prikl Bot Gen Sel Leningrad 28(I):417-508 (in Russian) 